\title{
Identification of seismic doublets occurred on Rudna mine, Poland
}

\author{
Lukasz Rudziński $^{1} \cdot$ Janusz Mirek $^{1} \cdot$ Grzegorz Lizurek $^{1}$
}

Received: 13 February 2017/ Accepted: 27 March 2017/Published online: 6 April 2017

(C) The Author(s) 2017. This article is an open access publication

\begin{abstract}
Seismic events with similar focal mechanisms and similarity of Green's functions exhibit common waveform shapes recorded on the same seismic station. The similarity of seismograms can also be observed in the case of man-induced seismicity on the continuous excavated area. In this work, we focused on strong and potential mininginduced seismic doublets, our study was using concepts of signal analysis, using an in-mine network with quite low dynamic range. Since in such case records for strong events are usually affected by clipping, signal analysis were performed with both raw signal cross-correlation (CC) and binary signal cross-correlation (BCC). We found that for events which fulfilled the established criteria, waveform similarities are significantly higher than for other possible doublets. Using BCC and CC approaches, we noticed crucial influences of double couple nodal planes' as well as $\mathrm{P}$ and T axis orientations on waveform similarities although the focal mechanisms were characterized by very high non-double couple components. Finally analysis confirmed that human activity represented by mining is able to produce strong $(M>3)$ repeating mining tremors.
\end{abstract}

Institute of Geophysics, Polish Academy of Sciences; (C2015 Author(s). This is an open access article distributed under the Creative Commons Attribution-NonCommercial-NoDerivs license, http://creativecommons.org/licenses/by-nc-nd/3.0/.

Łukasz Rudziński

rudzin@igf.edu.pl

Janusz Mirek

jmirek@igf.edu.pl

Grzegorz Lizurek

lizurek@igf.edu.pl

1 Institute of Geophysics, Polish Academy of Sciences, Warsaw, Poland
Keywords Mining induced seismology $\cdot$ Seismic doublets $\cdot$ Seismic signal

\section{Introduction}

The seismic signal recorded on a seismological network contains a lot of information needed to understand source physics. Of greatest importance are seismic phases used to solve for hypocenter location, focal mechanism or velocity model. Even a simple view of seismograms can provide some advanced analysis. One of the most interesting signal based studies are those dealing with repeated earthquakes with common shapes of recordings and clustered on particular areas. Doublets or more wider multiplets of events are often observed on active tectonic zones (e.g., Kagan and Jackson 1999), low-seismicity and volcanic areas (e.g., Gregersen et al. 2007; Quintanar et al. 2004) or human induced seismicity (e.g., Gibowicz 2006; Wehling-Benatelli et al. 2013) and provide a possibility to improve seismological analysis. Some conditions have to be fulfilled for multiplets in a sense of waveform similarities (Geller and Mueller 1980): two events should have almost the same location, with separation less than one quarter of the shortest wavelength $(\lambda / 4-$ criterion) also both source mechanisms and source time functions (STF) should be very similar. Such conditions might have a direct physical interpretation and the most popular is that similar earthquakes occurred on the same part of fault by rerupturing of the same asperity at a different time. This simple concept provides a lot of possibilities to improve seismological studies, from the new events' location procedures up to new conceptual source models (e.g., Poupinet et al. 1984; Got et al. 1994; Waldhauser and Ellsworth 2000; Anooshehpoor and Brune 2001; Schaff and Waldhauser 
2005; Baisch et al. 2008; Rudziński and Dębski 2011; Spottiswoode and Milev 1998; Godano et al. 2015).

In contrast to natural earthquakes, the mining induced events never occur without human activity which produces fast changes of stress distribution within rocks close to excavation panels (Gibowicz and Lasocki 2001). Even though dynamic response of the rock to industrial activity can change the velocity model, typical pattern of similar earthquakes might be observed in different induced environments (Evans et al. 2005). Due to clustering of the induced seismicity, waveform similarities might be treated as a good indicator of processes responsible for rock failure. It is well known that mining-induced seismicity tends to cluster in space and time (Gibowicz and Lasocki 2001). Clustering can be also observed when one is dealing with moment tensors (MT) for a number of close-spaced induced tremors in hard coal mining (Cesca et al. 2013; Sen et al. 2013). Analysis of similar tremors (Wehling-Benatelli et al. 2013) also showed that it might be a useful tool to indicate different types of failures caused by coal seam exploitation.

Multiplets and doublets of seismic events are also not exceptional in Polish copper mines. Based on catalogues studies, Gibowicz (2006) developed essential criteria characterizing multiplets in this particular area. Hypocenters of two events are separated by no more than $200 \mathrm{~m}$, the difference in origin time is not longer than 20 days, and the difference in moment magnitude is not larger than 0.15 . The study found that in the Rudna mine-one of the analyzed copper mines, 11 doublets, 4 triplets and 1 quadruplet were recorded in 2004 on different mining panels (Gibowicz 2006). In 2010, Rudna mine started excavation on the new mining panel no. XX/1 (Fig. 1). The panel was not affected by previous work. During excavation eight strong induced events with $M>3$ occurred and gave a possibility to provide an analysis of possible doublets among strong mining tremors. Directly following Gibowicz's criteria, we found and studied possible seismic multiplets using waveforms analysis of records from in-mine network. Even though the network is dense enough to locate sources with epicentral errors less than $100 \mathrm{~m}$, the low dynamic range influences seismograms by clipping. This is a factor which must be considered during signal analysis. In this paper, we try to deal with this problem and finally we summarize results obtained in this case study. Our investigation redefines the criteria for multiplets for clustered events occurring in Polish copper mines.

\section{Site and data description}

The Rudna mine is a deep copper mine belongs to the Legnica Głogów Copper District located on southwest Poland. Seismicity in the mine is quite strong with more

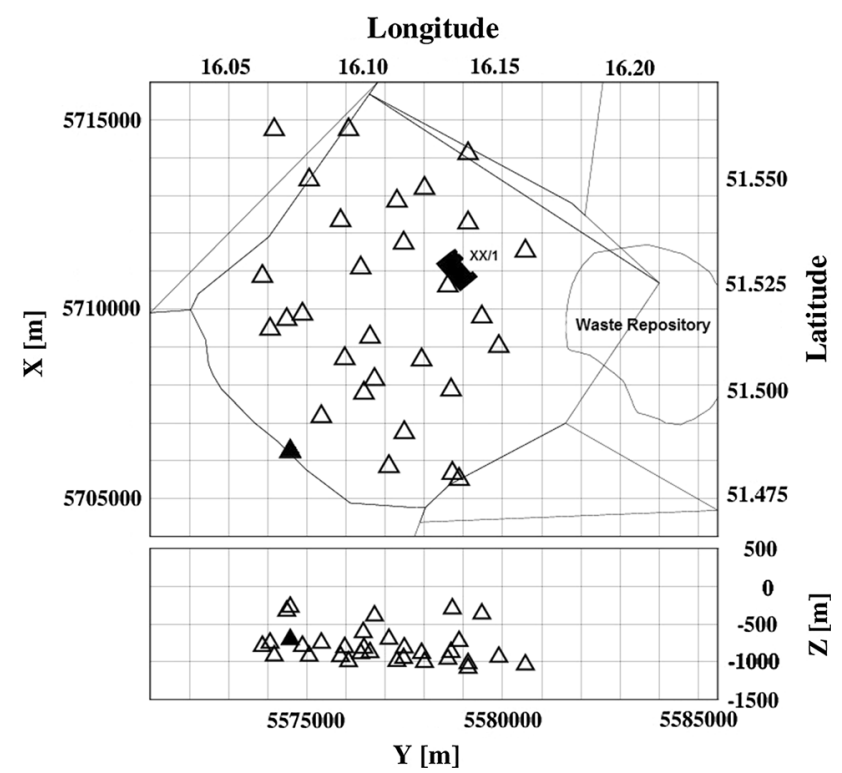

Fig. 1 The map of the Rudna mine seismic network (triangles) and the mining panel $\mathrm{XX} / 1$. Waveforms overlaying is shown for black fulfilled station (more details in text)

than 1000 events with $M>1.5$ recorded every year. An ore level is located at the depth from 900 to $1200 \mathrm{~m}$ and a copper is, at the same time, excavated from more than five mining panels. The XX/1 was excavated between 2010 and 2012. The productive level of panel $X X / 1$ of Rudna mine is located at the depth of about $1100 \mathrm{~m}$ and is overlain by some 60-92 m thick dolomite layer followed upwards by rigid anhydrite strata of around $160 \mathrm{~m}$ thickness. Below the deposit is a layer of hard Rotliegendes sandstones of about $300 \mathrm{~m}$ thickness. Ore is extracted by means of a room-andpillar exploitation system. From 2010 to 2012, the XX/1 mining panel in the Rudna copper mine was struck with several strong seismic events (Orlecka-Sikora et al. 2014). Based on Gibowicz (2006) criteria, we decided to select eight events (Table 1; Fig. 2) for further analysis of possible doublets existence. Our work was facilitated by the mining catalogue obtained from records of the underground seismic network operated in the Rudna mine. The initial events location provided by mining geophysical surveys were corrected using the location procedure worked with probabilistic inverse approaches, the algorithm already tested in the Rudna mine (Rudziński and Dębski 2011). The final hypocentres location with errors for particular coordinates are included in Table 1. While epicentre coordinates are estimate with high precision, accuracy in depth is much lower. Anyway we believe that all events have a similar origin (mining induced) and occurred on the similar depth.

The seismicity in the Rudna mine is continuously monitored by a local seismic network (Fig. 1). The network belongs to the mine and consists of 32 short-period 
Table 1 The list of strong seismic events selected as possible doublets

\begin{tabular}{lllllllll}
\hline Event & $X$ & $\Delta X$ & $Y$ & $\Delta Y$ & $Z(\mathrm{~m})$ & $\Delta Z$ & $M_{\mathrm{w}}$ & $R$ \\
\hline Ev1:26.06.2010 & 5711101 & 50 & 5578981 & 55 & -930 & 240 & 3.5 & 206 \\
Ev2:13.11.2010 & 5711112 & 50 & 5578965 & 50 & -975 & 220 & 3.3 & 181 \\
Ev3:18.12.2010 & 5711151 & 50 & 5578798 & 50 & -827 & 235 & 3.4 & 167 \\
Ev4:20.01.2011 & 5711071 & 55 & 5578987 & 50 & -897 & 260 & 3.1 & 192 \\
Ev5:20.01.2011 & 5711197 & 55 & 5578811 & 50 & -827 & 235 & 3.5 & 206 \\
Ev6:08.06.2011 & 5710981 & 45 & 5578844 & 45 & -941 & 260 & 3.5 & 160 \\
Ev7:05.10.2011 & 5710911 & 55 & 5578682 & 55 & -949 & 290 & 3.3 & 188 \\
Ev8:11.03.2012 & 5710866 & 60 & 5578701 & 55 & -882 & 300 & 3.4 & 208
\end{tabular}

$X$ and $Y$ are local coordinates in Cartesian system, $Z$ is a source depth in meters, $\Delta X, \Delta Y, \Delta Z$ are location errors in meters. $M_{\mathrm{w}}$ is a moment magnitude while $R$ is a foci radius

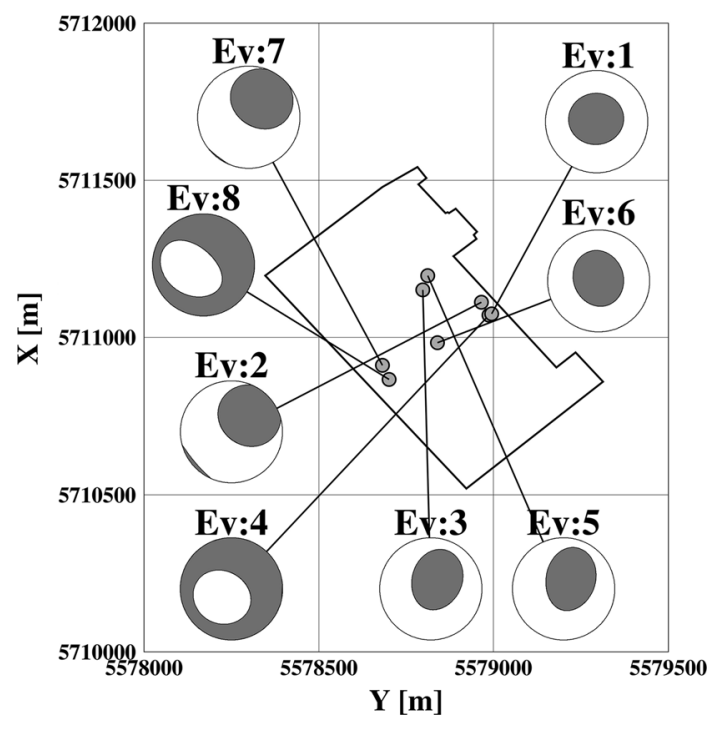

Fig. 2 The map of proposed seismic doublets and its full MT solutions

vertical seismometers Willmore MK-III. Even though the number of stations and $500 \mathrm{~Hz}$ sampling rate give an opportunity to locate hypocenters within an accuracy of about $50 \mathrm{~m}$ in epicentral distance and $150-200 \mathrm{~m}$ in depth (Rudziński and Dębski 2011), less than $70 \mathrm{~dB}$ dynamic ranges can cause clipping of seismic signals. This condition is especially obstructive when a very strong event is considered.

For selected events from Table 1, two source parameters, namely moment magnitude $M_{\mathrm{w}}$ and source radius, have been determined using spectra of $\mathrm{P}$ and $\mathrm{S}$ waves using the relationship between spectral and Brune's source parameters. All estimations were performed using the formalism of Andrews (1986), Brune (1970, 1971) and Wyss and Brune (1968), described by Gibowicz and Kijko (1994) and Niewiadomski (1997). According to those formalisms, moment magnitude is obtained with seismic moment which is directly related to the low frequency level of the far field displacement spectrum:
$M_{0}=\frac{4 \pi \rho c^{3} R \Omega_{0}}{F_{\mathrm{c}} R_{\mathrm{c}} S_{\mathrm{c}}}$

$\rho$-density of the source area, $c-\mathrm{P}$ or S wave velocity in source, $R$-source-receiver distance, $\Omega_{0}$-spectral level, $R_{\mathrm{c}}$-free surface correction, $S_{\mathrm{c}}$ - site correction, $F_{\mathrm{c}}-\mathrm{P}$ or S wave coefficient.

Source radius $r_{0}$ was estimated using Madariaga's (1976) circular fault model; in such formalism (Brune 1970), the source radius is inversely proportional to the corner frequency $f_{\mathrm{c}}$ of $\mathrm{P}$ or $\mathrm{S}$ wave:

$r_{0}=\frac{K_{\mathrm{c}} \beta_{0}}{2 \pi f_{\mathrm{c}}}$

where $K_{\mathrm{c}}$ is a constant depending on source model and $\beta_{0}$ is $\mathrm{S}$-wave velocity in the source region. The relevant parts of seismograms of $\mathrm{P}$ and $\mathrm{S}$ waves were selected manually, and then transformed by Fast Fourier Transformation (FFT). The resulting amplitude spectra were corrected for attenuation effects with $Q=400$ and 200, respectively, for P and $\mathrm{S}$ waves. For further calculations we set velocities of $\mathrm{P}$ and $S$ waves in source at $V_{\mathrm{p}}=5900 \mathrm{~m} / \mathrm{s}$ and $V_{\mathrm{s}}=3400 \mathrm{~m} / \mathrm{s}$. The station number used for analysis differ from 15 to 25 in case of P-wave and from 4 to 10 stations in case of S-wave according to the unclipped recordings.

The source radii $R$ of the studied events were between 160 and $208 \mathrm{~m}$ (Table 1), which corresponds to the corner frequency from 1.5 up to $3.5 \mathrm{~Hz}$. The source size estimates are not exceptional when compared with the average event source radius of the events from Rudna mine, which was mainly about $200 \mathrm{~m}$ (Lizurek and Wiejacz 2011).

In next step for selected events a focal mechanisms were calculated using the full moment tensor (MT) inversion in time domain. Calculations of the full MT from the records of the underground network of the mine were performed with the use of FOCI software (Kwiatek et al. 2016). The input parameters are the amplitude and polarity information on the first P-wave displacement pulses. According to Fitch et al. (1980), De Natale et al. (1987) and Aki and 
Richards (2002), the recorded displacement for the P-wave phase is:

$\mathbf{U}^{\mathrm{P}}(\mathbf{x}, t)=\frac{\boldsymbol{\gamma} \cdot \dot{\mathbf{M}}\left(t-\frac{r}{\alpha}\right) \cdot \boldsymbol{\gamma}}{4 \pi \rho \alpha^{3} r} \mathbf{l}$

where $\rho$ is the average medium density, $r$ is the sourcereceiver distance, $\alpha$ is the average velocity of the $\mathrm{P}$ wave, $\mathbf{M}$ is the seismic moment tensor, $\mathbf{l}$ is the $\mathbf{P}$ wave direction at the receiver, and $\gamma$ is the $\mathrm{P}$-wave direction at the source.

The source time function (STF) was based on the Haskell's source model (Haskell 1953):

$\dot{s}=\begin{array}{cc}1 / T, & 0<t<T \\ 0, & \text { elswhere }\end{array}$

where $T$ is the rupture time.

The MT is obtained by solution of a set of $N$ equations of type (3). The deviatoric, pure shear and full MTs (Table 2) were calculated using the L2 norm as a measure of the misfit (Wiejacz 1992; Awad and Kwiatek 2005). The recorded first arrivals may be of different types: direct $P$ waves or refracted waves from the overlying anhydrite layer or the thick strata of sandstone underlying the ore deposit. This is caused by the geological situation. The layers are almost flat, the dip of the layers being about $4^{\circ} \mathrm{NE}$. The ore bearing strata are a dolomite layer of $60-90 \mathrm{~m}$ thickness. Above the ore bearing strata, there exists the evaporate series mainly composed of the anhydrite of $160 \mathrm{~m}$ thickness, and below the ore bearing strata there is a sandstone layer of about $300 \mathrm{~m}$ thickness.

\section{Doublets analysis}

In Fig. 2, all doublets are shown with its full MT solutions while Figs. 3, 4, 5 and 6 shows the corresponding fault plane solutions, i.e., the double-couple (DC) contribution (see Table 2). Based on the results of the moment tensor inversion, four doublets are proposed (Figs. 2, 3, 4, 5 and 6).
Figures 3, 4, 5 and 6 show the following pairs, Ev2-Ev4, Ev3-Ev5 and Ev7-Ev8 exhibit significant similarities in nodal planes distributions and Ev1-Ev6 with similar MT solutions. The full MTs (Fig. 2; Table 2) for Ev1-Ev6, is characterized by almost the same decomposition and the smallest DC component among four events pairs. This observation is not an extraordinary feature, since the nondouble-couple (non-DC) events are quite often observed in induced seismicity (Gibowicz 2009, Rudziński et al. 2016). Comparison between Figs. 6 and 2 show that although the MTs of events 1 and 6 are very similar, the corresponding DC solutions are very different.

Both the hypocenter location (inter-event distances) and other source parameters (Tables 1, 2 and 3) support our choice of possible doublets. Final inspections suggest the following four doublets:

- Ev1 and Ev6,

- Ev2 and Ev4,

- Ev3 and Ev5,

- Ev7 and Ev8.

These pairs fulfilled criteria developed by Gibowicz (2006).

Since the highest dominant frequency for $\mathrm{P}$ wave is $3.5 \mathrm{~Hz}$ and based on local average velocity model the $\mathrm{P}$ wave velocity is $5.5 \mathrm{~km} / \mathrm{s}$, the shortest distance satisfying the $\lambda / 4$ criterion should be less than about $390 \mathrm{~m}$. Note that all inter-event distances fit into these limits (Table 3). The last parameter characterizing seismic doublets in the Rudna mine is interevent time. Since this parameter is very difficult to set up, in the previous studies has been selected arbitrarily as 20 days. In this work, we assumed that it is significantly less important than the distance criterion. Our selected doublets are characterized with following time differences: Ev2-Ev4: 28 days, Ev3-Ev5: 33 days, Ev7-Ev8: 127 days and Ev1-Ev6: 347 days. Even the shortest time distance exceeded 20 days criterion.

Table 2 The full MT solutions, scalar seismic moment and corresponding moment magnitude $\mathrm{M}_{\mathrm{w}}$ for the selected seismic events

\begin{tabular}{|c|c|c|c|c|c|c|c|}
\hline \multirow[t]{2}{*}{ Event } & \multicolumn{7}{|c|}{ Focal mechanism solution full moment tensor } \\
\hline & ISO $(\%)$ & $\operatorname{CLVD}(\%)$ & $\mathrm{DC}(\%)$ & $\begin{array}{l}\text { Nodal plane A } \\
\text { (strike/dip/slip) }\end{array}$ & $\begin{array}{l}\text { Nodal plane B } \\
\text { (strike/dip/slip) }\end{array}$ & $\begin{array}{l}\text { Scalar seismic } \\
\text { moment }(\mathrm{Nm})\end{array}$ & $\mathrm{M}_{\mathrm{w}}$ \\
\hline Ev:1 & 28 & 55.3 & 16.7 & $84 / 50 / 90$ & $265 / 40 / 91$ & $1.81 \cdot 10^{14}$ & 3.5 \\
\hline Ev:2 & 24 & 61.5 & 14.5 & $127 / 85 /-80$ & $246 / 11 /-151$ & $9.2 \cdot 10^{13}$ & 3.2 \\
\hline Ev:3 & 30.9 & 32.3 & 36.8 & $185 / 53 / 68$ & $39 / 43 / 116$ & $1.59 \cdot 10^{14}$ & 3.5 \\
\hline Ev:4 & -30.4 & -46.0 & 23.6 & $304 / 67 /-82$ & $105 / 24 /-107$ & $5.50 \cdot 10^{13}$ & 3.1 \\
\hline Ev:5 & 26.6 & 29.4 & 43.9 & $180 / 56 / 68$ & $36 / 40 / 119$ & $1.8 \cdot 10^{14}$ & 3.5 \\
\hline Ev:6 & 24 & 47.5 & 28.5 & $164 / 47 / 84$ & $353 / 43 / 96$ & $2.13 \cdot 10^{14}$ & 3.5 \\
\hline Ev:7 & 7.7 & 54.8 & 37.5 & $124 / 87 / 93$ & $259 / 4 / 45$ & $9.35 \cdot 10^{13}$ & 3.3 \\
\hline Ev:8 & -18.4 & -20.8 & 60.8 & $314 / 68 /-77$ & $104 / 26 /-118$ & $1.30 \cdot 10^{14}$ & 3.4 \\
\hline
\end{tabular}

Parts of the full MT: ISO isotropic, CLVD, DC 

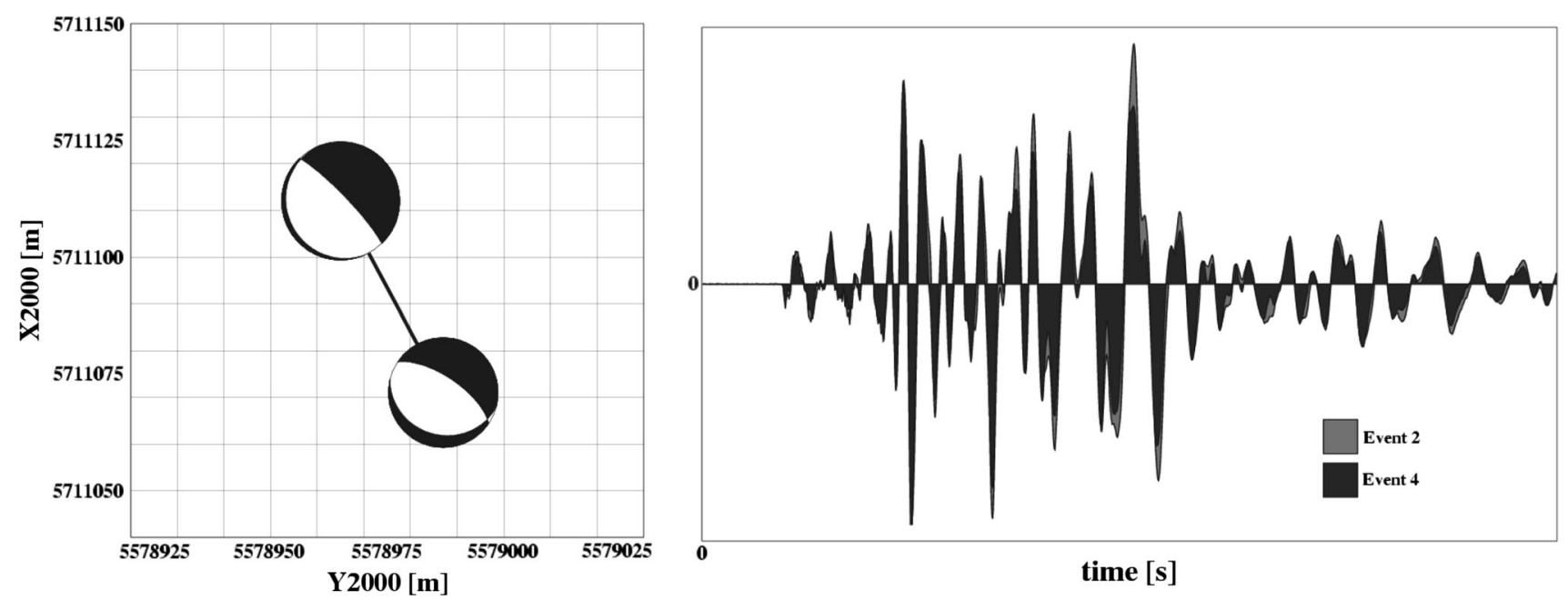

Fig. 3 Doublet Ev2-Ev4. DC solutions (left) and seismograms overlapping recorded on the same station
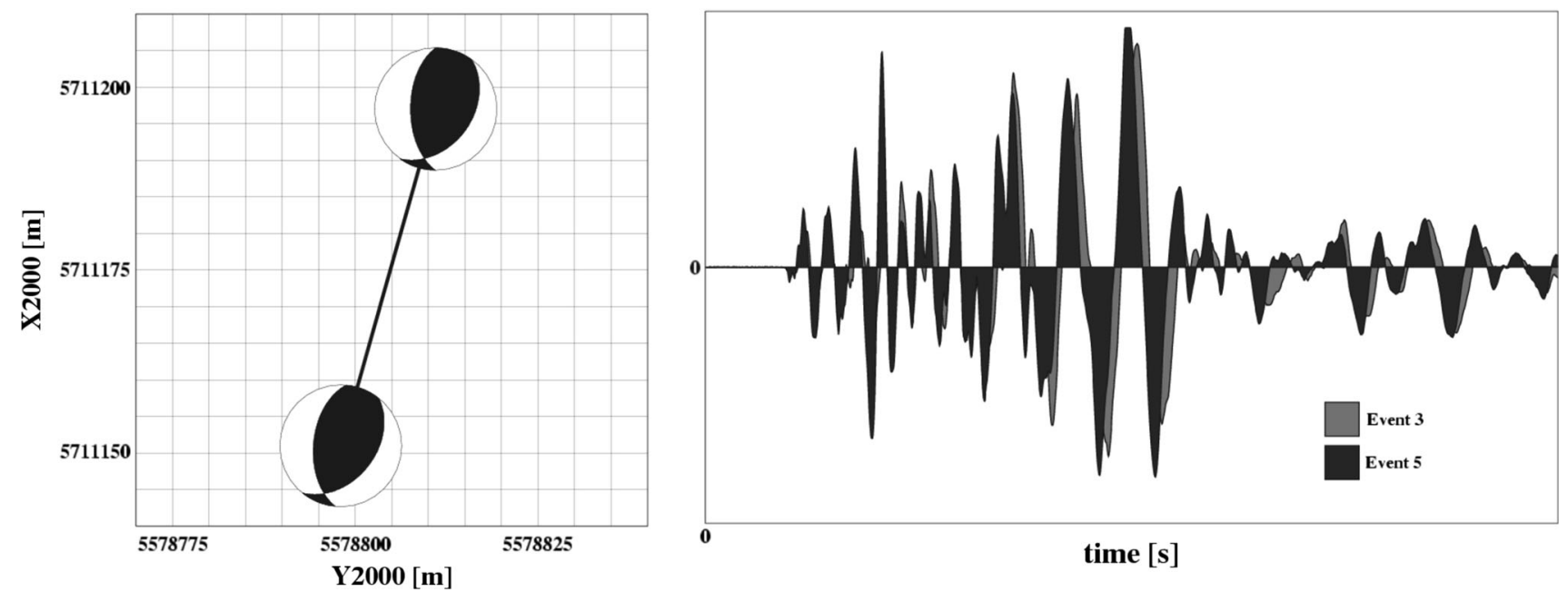

Fig. 4 Doublet Ev3-Ev5. DC solutions (left) and seismograms overlapping recorded on the same station
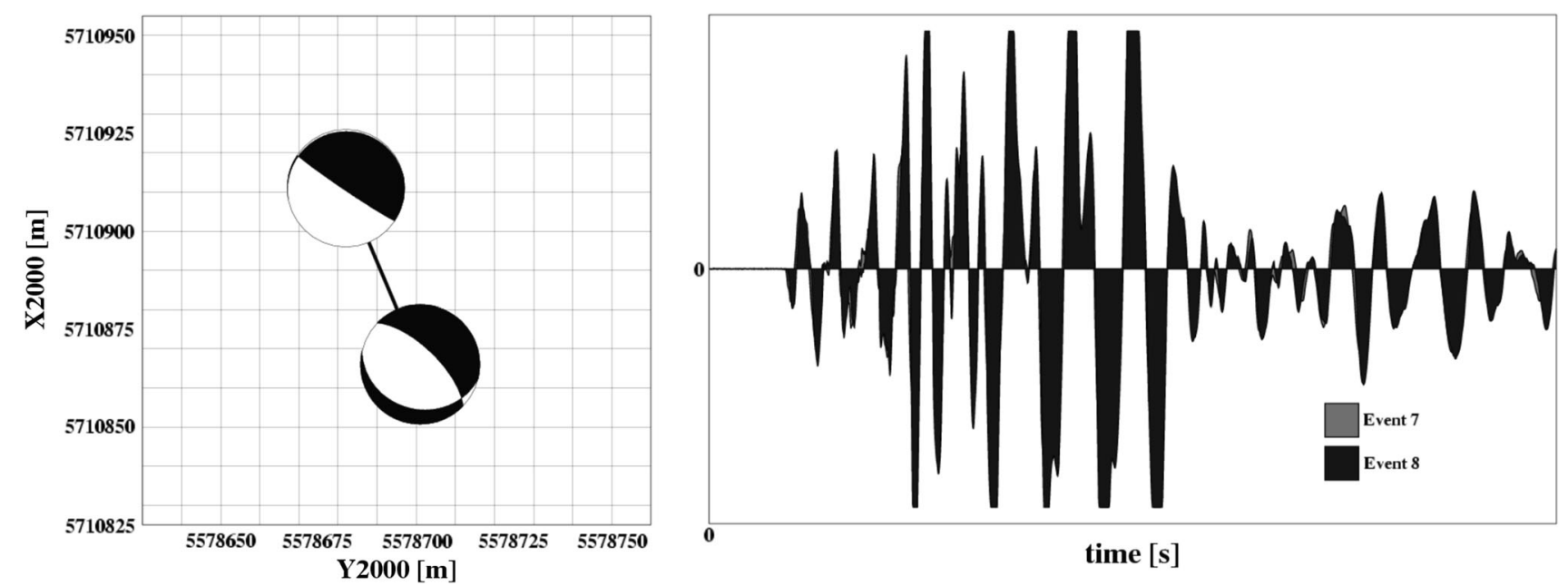

Fig. 5 Doublet Ev7-Ev8. DC solutions (left) and seismograms overlapping recorded on the same station 

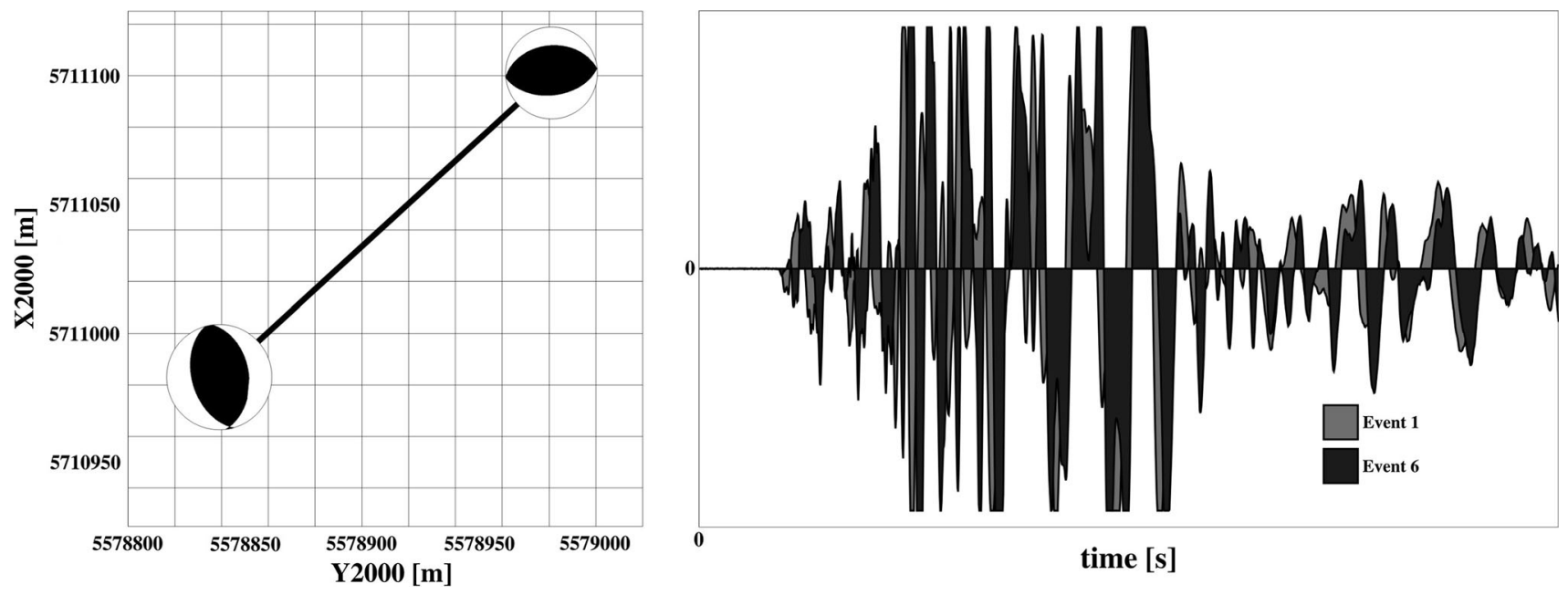

Fig. 6 Doublet Ev1-Ev6. DC solutions (left) and seismograms overlapping recorded on the same station

Table 3 Doublets selection based on distances between hypocenter locations $\Delta D$ and differences in moment magnitude $\Delta M_{\mathrm{w}}$

\begin{tabular}{lrl}
\hline Doublet & \multicolumn{1}{c}{$\Delta \mathrm{D}$} & $\Delta \mathrm{M}_{\mathrm{w}}$ \\
\hline Ev1-Ev6 & $193 \mathrm{~m}$ & 0 \\
Ev2-Ev4 & $80 \mathrm{~m}$ & 0.1 \\
Ev3-Ev5 & $48 \mathrm{~m}$ & 0.1 \\
Ev7-Ev8 & $83 \mathrm{~m}$ & 0.1 \\
\hline
\end{tabular}

Two groups of doublets can be now considered. The first one consists of three pairs: Ev2-Ev4, Ev3-Ev5 and Ev7Ev8. The second one contains just Ev1-Ev6 doublet. For selected doublets, we propose the following seismic signals analysis. On the first step let us choose one the most adequate seismic station and roughly compare the seismograms obtained for two events from each pair. The selected sensor should be far enough from clusters centroid to avoid some recordings problems especially seismograms clipping in S-wave coda. To show how the waveforms overlap each other, we used a station located about $6 \mathrm{~km}$ away from the $\mathrm{XX} / 1$ mining panel (black triangle in Fig. 1). The results are gathered in Figs. 3, 4 and 5 (first group) and in Fig. 6 for the last pair.

The first group of events exhibits very interesting features in both focal mechanisms and waveform similarities. It should also be noted that the rough line connecting two events forming doublet, corresponds to directions of dominant discontinuities in the mining panel (Mining Geophysical Survey personal information 2015). This observation suggests that for this group the DC-part rupture on pre-existing discontinuities. The most important conclusion is that waveforms for doublets observed in this group are almost identical, even though tremors have, among pairs, other magnitude ranges.

Some other conclusions follow from Fig. 6. The pair Ev1-Ev6 in comparison with the previous doublets has different fault plane orientation and the waveforms not overlap each other. On the other hand, the complete MT results plotted on a lower hemisphere are identical between Ev1 and Ev6 (Fig. 2). Moreover, based on miners observations, the line between these two events does not correspond to any existing geological discontinuity. These two features are very interesting, when we take into account almost the same MT decomposition and suggest that the focal mechanisms for both events are rather connected with pillar destruction without contribution dealing with preexisting lines of weakens, what is not exceptional at the Rudna mine (Lizurek and Wiejacz 2011). One can make a statement that Ev1-Ev6 should not be treated as a doublet.

It is worth to calculate the parameter $\eta$ which measures the degree of fault rupture overlapping (Kagan and Jackson 1999),

$\eta=\frac{L_{1}+L_{2}}{2 D}$

where $L$ represents the rupture length, considered as double source radii $R$ while $D$ is a distance between events hypocenters. The value of $\eta$ larger than 1.0 suggests that the rupture zones overlap. Table 4 includes $\eta$ for all analyzed pairs. All doublets, including Ev1-Ev6, have $\eta$ larger than 1 strongly suggesting overlapping of its rupture zones. For the first group $\eta$ coefficients, however, are more than four times greater that for pair Ev1-Ev6. Let us also note that if we consider the distances including the higher location errors in epicentral coordinates, only pair Ev1Ev6 has a $\eta$ less than 1.

The previous part was mostly based on visual inspection of seismic signals. Now, we are going to investigate waveforms similarities using signal analysis. This approach has many advantages, nevertheless very serious problem, namely signal clipping (Fig. 7) caused by network low 
Table 4 The parameter $\eta$ which measures degree of fault rupture overlapping

\begin{tabular}{llrl}
\hline Doublet & L1 + L2 & D & $\eta$ \\
\hline Ev1-Ev6 & 732 & 193 & 1.89 \\
Ev2-Ev4 & 746 & 80 & 4.66 \\
Ev3-Ev5 & 746 & 48 & 7.77 \\
Ev7-Ev8 & 792 & 83 & 4.77 \\
\hline
\end{tabular}

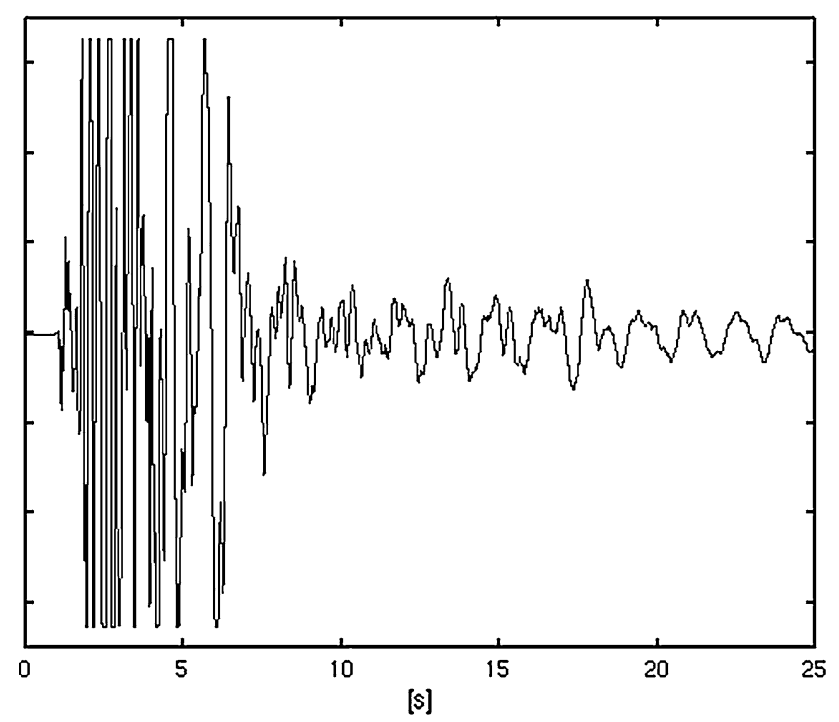

Fig. 7 Example of clipped signal recorded on selected seismic station

dynamic range is a factor influencing our investigation. To minimize this issue, we used not only normalized signal cross-correlation $C(\tau)(\mathrm{CC})$ (e.g., Schaff and Waldhauser 2005 and references therein):

$C(\tau)=\frac{1}{\sqrt{\sum_{n=0}^{N-1} X^{2}\left(t_{n}\right) \sum_{n=0}^{N-1} Y^{2}\left(t_{n}\right)}} \sum_{n=0}^{N-1} X\left(t_{n}\right) Y\left(t_{n}+\tau\right)$

where $X$ and $Y$ are two discrete time series of length $N$ and $\tau$ denotes the time lag but also binary cross-correlation (BCC) and frequency cross-correlation (FCC) both eliminate saturation effects. Analysis was done with seismic traces for all possible doublets-stations pairs. During analysis with CC method, to avoid signal clipping problems, correlation measurements were made just for $5 \mathrm{~s}$ windows lengths, $1 \mathrm{~s}$ before and $4 \mathrm{~s}$ after first arrivals. Next maximal values of correlation coefficients were used for further study.

The resulting CC coefficients were gathered into two types of figures. The first one includes histograms, which show a number of stations versus coefficient intervals. The second one describes spatial distributions of waveform similarities in the form of the map, where correlation coefficient intervals are sketched for each station. An overview of the normalized cross-correlation results are given in Figs. 8, 9, 10 and 11. Further all possible event pairs (28 cases without coefficients for pairs consist of the same event) were investigated toward average $\mathrm{CC}$ values. The values range between 0.3 and 0.8 . Only pairs Ev2Ev4, Ev3-Ev5, among all studied pairs were characterized by average $\mathrm{CC}$ equal or exceeding 0.6. In Fig. 12 (left), average $\mathrm{CC}$ coefficients are presented for all events.

As in the previous analysis, different doublets are characterized by different CC features. The pair Ev2-Ev4 exhibits not only high signal overlapping in selected channel but has also the highest average CC. The next two pairs, Ev3-Ev5 and Ev7-Ev8, have average CC $>0.6$, even though for doublet Ev7-Ev8 eight records have very small CC-below 0.2. On the other hand some stations for the pairs Ev7-Ev8 and Ev2-Ev4 reached CC values above 0.9 while for Ev3-Ev5 most signals have an CC 0.7. Let us note that northeastern stations exhibit smaller CC, especially in case of Ev1-Ev6; we expect that it can be, at least partially, caused by some random environmental and cultural seismic noise background. In some way, differences in background noises can be explained by a very large mining waste neutralization repository. The facility is located in the eastern part of the Rudna's area (see Fig. 1). The Ev1-Ev6 pair is characterized by the lowest average $\mathrm{CC}$, although the high similarity of the full MT solution with dominance of compensated linear vector dipole (CLVD) term and almost identical T-axis orientation. The main difference which can influence the signal $\mathrm{CC}$ is the nodal plane and $\mathrm{P}$-axis orientation whose strike differ by about $90^{\circ}$ in this case. These features of the rupture orientations were crucial for seismic wave radiation pattern of those events, which were obviously different according to the results of average $\mathrm{CC}$ of the studied signals. Since there is not a sufficient similarity in waveforms, the pair Ev1Ev6 is not a doublet.

For $\mathrm{CC}$ analysis we used just $5 \mathrm{~s}$ signals and for pair Ev7-Ev8 there is not direct evidence that obtained CC values denoted a doublet, we decided to support our double hypothesis by eliminating clipping effects. The technique is based on BCC methodology and in comparison with CC method uses the whole available signal data. This part of the data analysis consists of four steps concerning signals:

- Mean and trend removal,

- Ambient noise elimination by normalizing all amplitudes larger than a fixed value to zero,

- Median filtering

- Signal binarization using one-bit normalization method.

Figure 13 shows a raw seismograms (top), seismogram after signal processing (middle) and binary signal one-bit 

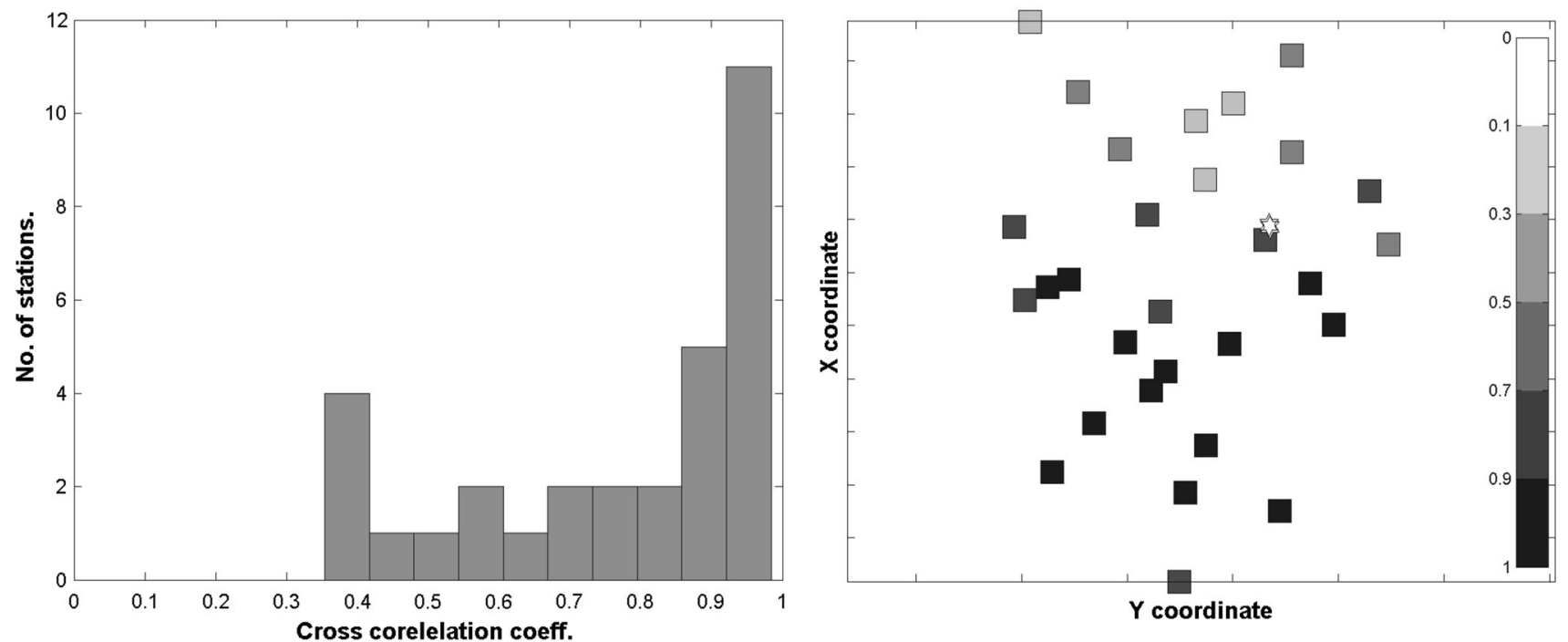

Fig. 8 Doublet Ev2-Ev4. Cross-correlation coefficients and its spatial distributions. The black square indicates the station with the highest correlation while white stars are epicenters
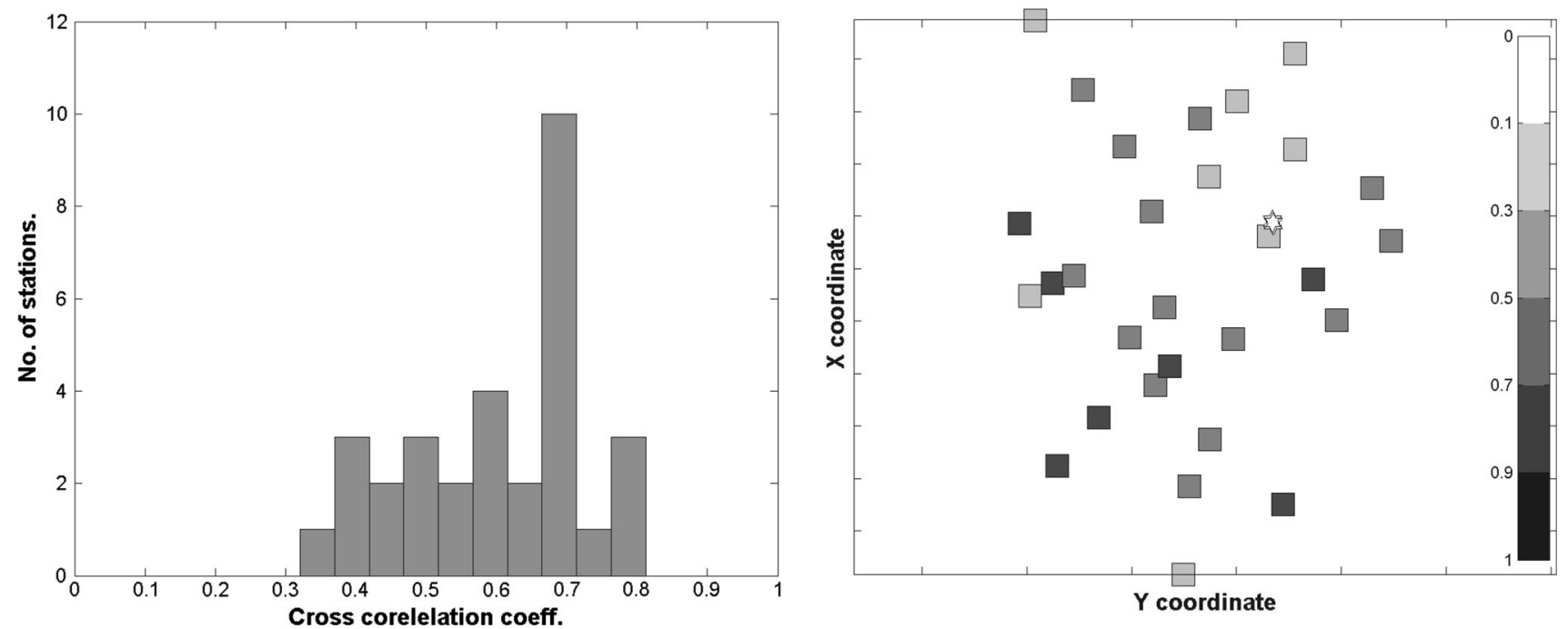

Fig. 9 Doublet Ev3-Ev5. Cross-correlation coefficients and its spatial distributions. The black square indicates the station with the highest correlation while white stars are epicenters

normalization (bottom) (Cupillard et al. 2011) for one selected event. For all possible events pairs maximal value of BCC coefficient were calculated for all stations. Results are collected in Fig. 12 (middle) as an average BCC coefficient. These results strongly support observation obtained with $\mathrm{CC}$ methodology. We noticed that the biggest BCC average values are connected with the proposed doublets including Ev7-Ev8 except Ev1-Ev6. Our results suggest that the BCC approach can be valuable analysis for data affected by clipping. It will be very important issue in case of clipped records within seconds after $\mathrm{P}$ wave first arrival.

Third method used in our studies was the FCC. In this method authors calculate correlation between histograms of frequencies of signals obtained in previous step.
Frequency vector was calculated as $1 /\left(k_{i} \cdot \mathrm{d} t\right)$, where $\mathrm{d} t$ is sampling rate, and $k_{i}$ is number of following samples without changing a sign. Histogram was calculated with step $0.05 \mathrm{~Hz}$. Results are gathered in Fig. 12 (right). The results obtained with the $\mathrm{FCC}$ are more complicated in comparison with the $\mathrm{CC}$ and the BCC solutions. The similarities for pairs Ev2-Ev4 and Ev7-Ev8 are clearly visible. On the other hand the pair Ev3-Ev5 has average coefficient even smaller than pair Ev1-Ev6. Moreover, there are few more possible pairs like Ev1-Ev7 or Ev1Ev8 with quite high coefficients. Nevertheless, when the results from tree methods are gathered together, we clearly see that doublets Ev2-Ev4, Ev3-Ev5 and Ev7-Ev8 are similar in the sense of seismograms similarities. 

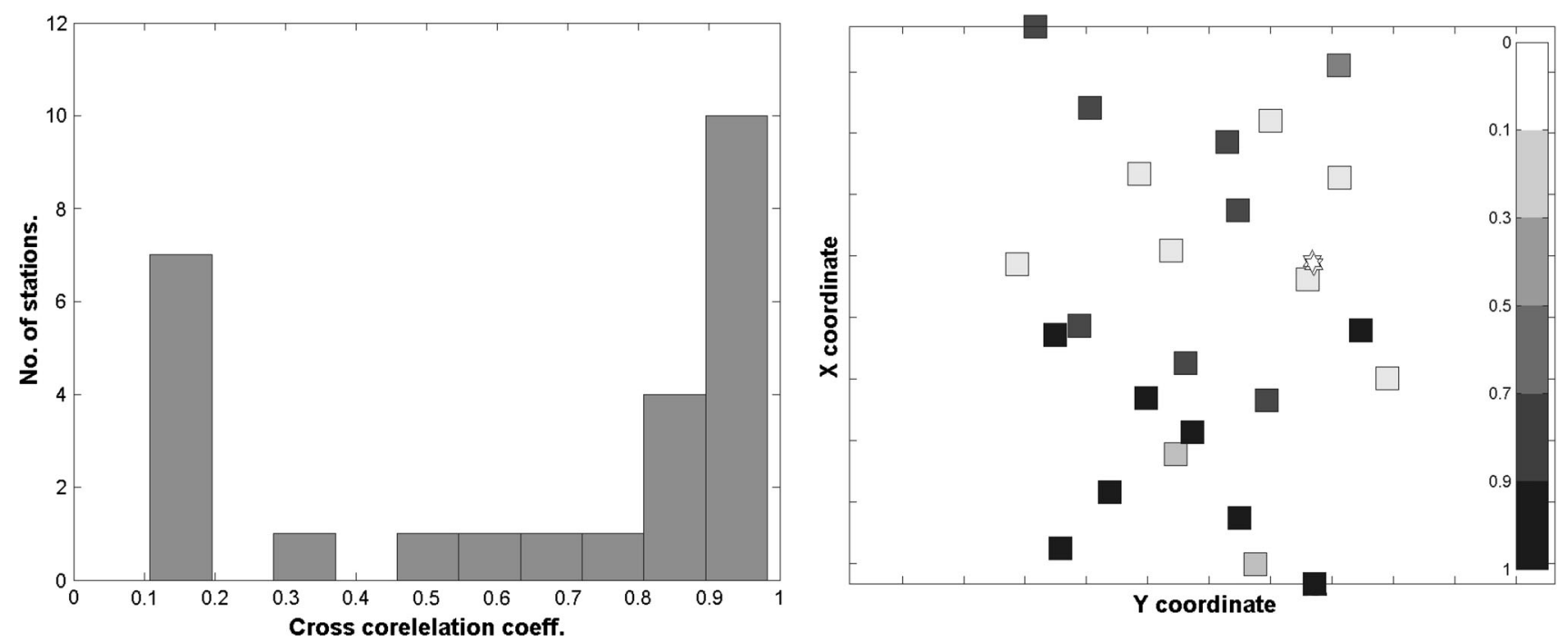

Fig. 10 Doublet Ev7-Ev8. Cross-correlation coefficients and its spatial distributions. The black square indicates the station with the highest correlation while white stars are epicenters
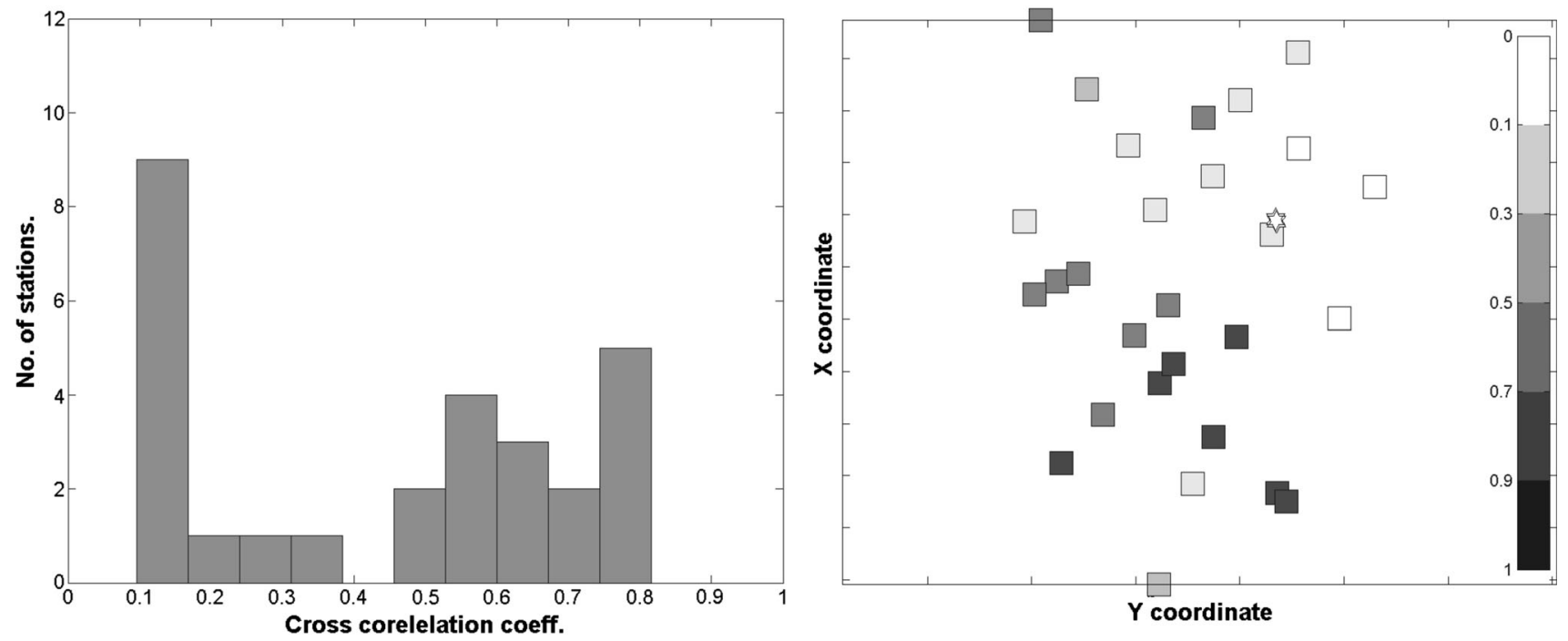

Fig. 11 Doublet Ev1-Ev6. Cross-correlation coefficients and its spatial distributions. The black square indicates the station with the highest correlation while white stars are epicenters

\section{Discussion and conclusions}

Our study shows that an analysis of waveform similarities can be a robust method to distinguish two similar induced seismic events occurring on mining area even in case of data set recorded on network with low dynamic range. Among all possible combinations of events pairs, just three doublets exhibit signals analysis features to be treated as doublets and all of them belong to the first group. Our expectation is that average similarity threshold should be above $\mathrm{CC}>0.6$. The same conclusions can be derived if we used BCC/FCC analysis.
Some very interesting features observed within an analysis of particular doublets should be concluded. Apart from the most obvious, namely the influence of events separations and general types of focal mechanisms to waveform similarities, we can observe very strong influence coming from nodal planes orientations resulting from the main stress axes orientation. It is especially interesting since the non-DC part of the full MT solutions within the studied pairs was not influencing the result of average $\mathrm{BCC} / \mathrm{CC} / \mathrm{FCC}$ analysis as much as the nodal plane orientations differences. This observation suggests that non-DC parts in the full MT could be contaminated by noise but on 

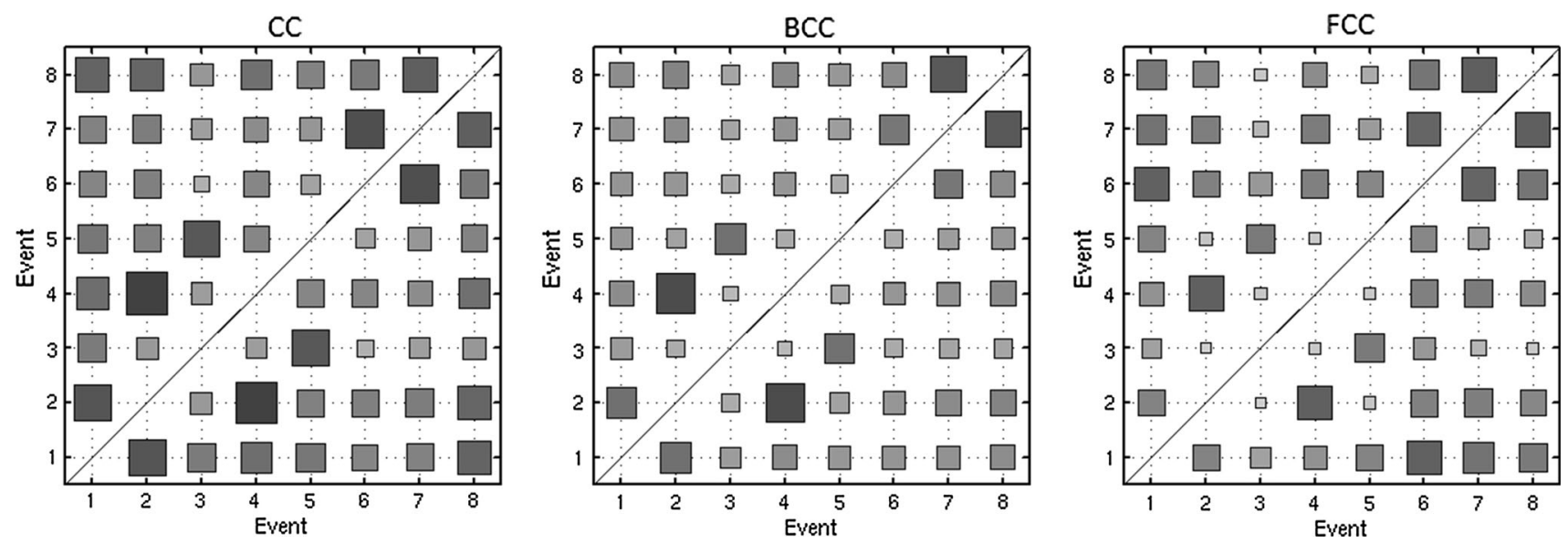

Fig. 12 Graphical comparison of averaged correlation coefficients using all three methods
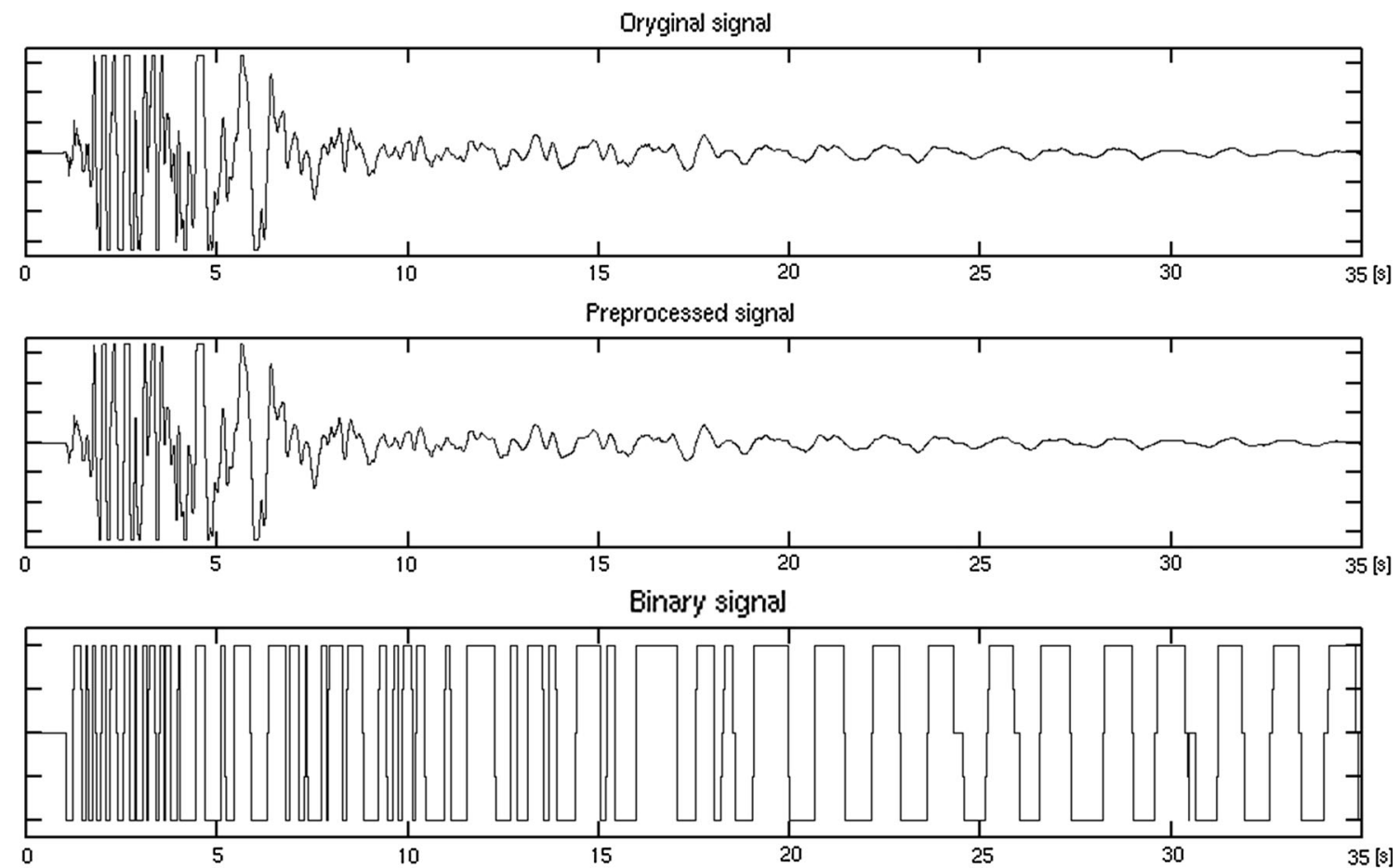

Fig. 13 Seismic signal binarization. Top - raw seismogram, middle-seismogram after first three steps of analysis (see for details in text), bottom - binary signal

the other hand the thorough study provided by OrleckaSikora et al. (2014) states that source mechanisms occurred on the panel XX/1 are better explained by the full MT (tensile source mechanism) and extended source rather than DC part of point source full MT. Let us note that the difference in strike of the nodal plane was crucial. From four pairs taken under investigation, the only pair with low average $\mathrm{BCC} / \mathrm{CC} / \mathrm{FCC}$ was the one with significantly different nodal plane strikes. Knowing that, we calculate a radiation patterns for all pairs caused by slip on fault. We followed with method described by Kwiatek and Ben-Zion
(2013) and in Fig. 14 we present the radiation patterns for Ev1 and Ev6. The pair has small CC, especially on northeastern part of the network (Fig. 11). It can be noticed that the radiation pattern can be another feature responsible for that. The inter event time is a less influencing factor. Even though the doublet with the highest $\mathrm{CC}$ occurred within just 28 days, next two doublets have time differences up to 127 days and measured CC higher than 0.6. We can conclude that the $\mathrm{P}$ and $\mathrm{T}$ axis orientation and, therefore, the nodal planes of DC solution of the full MT plays the most significant role in the similarity analysis. The 

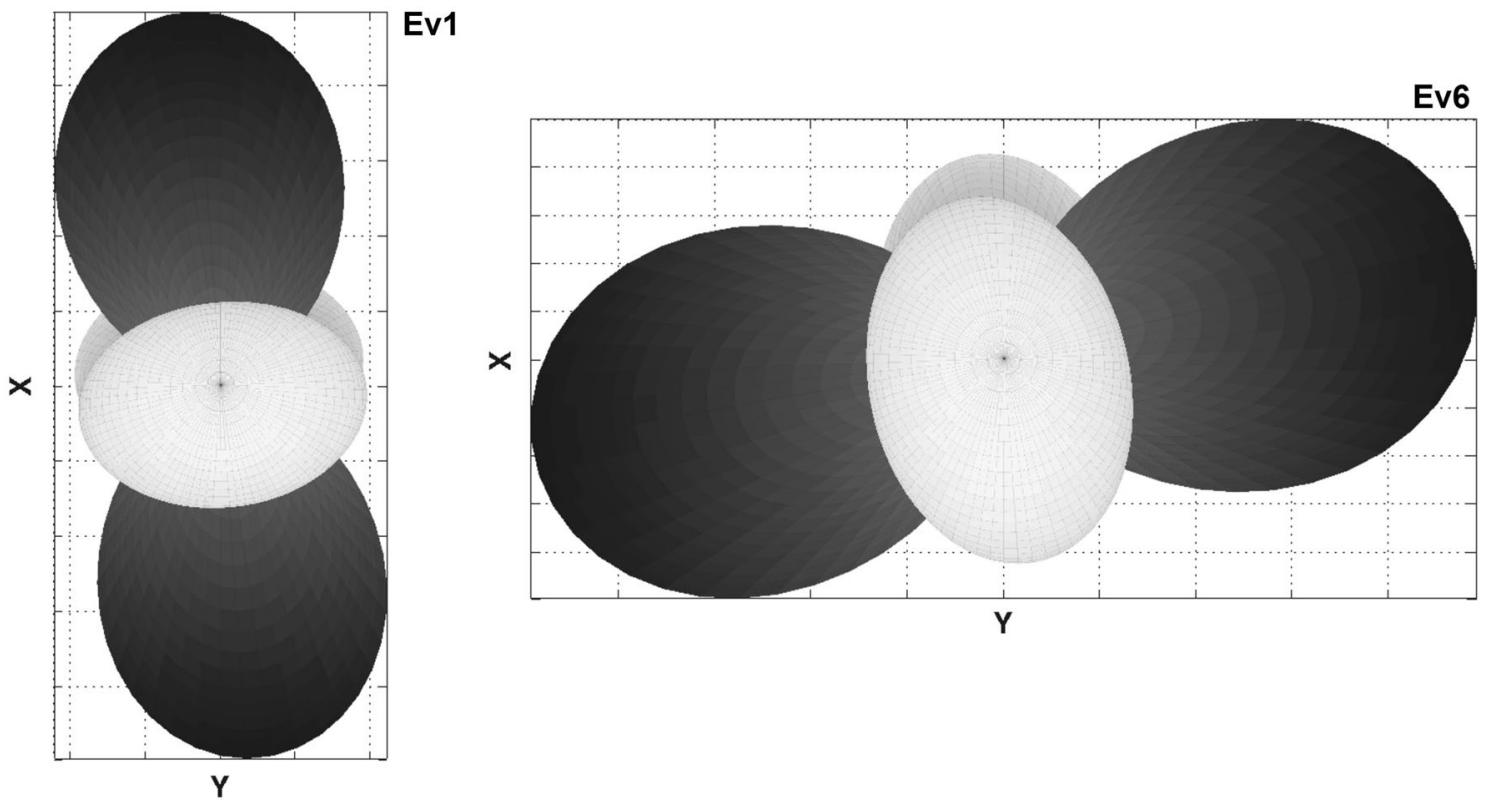

Fig. 14 Radiation patterns dealt with fault orientations of pair Ev1 and Ev6. The differences of pressure axis (black axis) could be considered as responsible for smallest $\mathrm{CC}$ on the northeastern part of the network

more similar nodal planes and $\mathrm{P}, \mathrm{T}$ axis orientations the more similarity in waveforms we observed. Since the most similar pairs have nodal planes in accord with the main discontinuities in the mining panel, they probably followed the same rupture. This may be an important indicator of the rupture properties within the rocks in the particular mining environment.

The last but not least is that the BCC and FCC signal analysis work very well with clipped seismograms although the results obtained with the BCC much better support proposed doublets. The method should be especially valuable when clipping affects the whole record and $\mathrm{CC}$ with raw signal is hardly useful for studies. Results presented here could be treated as a first step to provide automated signals analysis to identify similar events on mining environments.

Acknowledgements We are very thankful to the "Rudna" copper mine for providing seismic data (catalogue and seismic signals) and technological information. The work was supported by statutory activities No. 3841/E-41/S/2017 of the Ministry of Science and Higher Education of Poland. Most of figures were prepared using the GMT package (Wessel and Smith 1998). Anonymous reviewers are appreciated for their valuable comments which were helpful in improving the article.

Open Access This article is distributed under the terms of the Creative Commons Attribution 4.0 International License (http://crea tivecommons.org/licenses/by/4.0/), which permits unrestricted use, distribution, and reproduction in any medium, provided you give appropriate credit to the original author(s) and the source, provide a link to the Creative Commons license, and indicate if changes were made.

\section{References}

Aki K, Richards PG (2002) Quantitative seismology. University Science Books, Sausalito

Andrews DJ (1986) Objective determination of source parameters and similarity of earthquakes of different size. In: Das S, Boatwright J, Scholz CH (eds) Earthquake source mechanisms, Maurice Ewing, vol 6. American Geophysical Union, Washington, D.C, pp 259-267

Anooshehpoor A, Brune JN (2001) Quasi-static slip-rate shielding by locked and creeping zones as an explanation for small repeating earthquakes at Parkfield. Bull Seismol Soc Am 91(2):401-403

Awad H, Kwiatek G (2005) Focal mechanism of earthquakes from June 1987 swarm in Aswan, Egypt, calculated by the moment tensor inversion. Acta Geophys Pol 53(3):275-291

Baisch S, Ceranna L, Harjes H-P (2008) Earthquake cluster: what can we learn from waveform similarity? Bull Seismol Soc Am 98(6):2806-2814. doi:10.1785/0120080018

Brune JN (1970) Tectonic stress and the spectra seismic shear waves from earthquakes. J Geophys Res 75:4997-5009

Brune JN (1971) Correction. J Geophys Res 76:5002

Cesca S, Dham T, Tolg Sen A (2013) Moment tensor clustering: a tool to monitor mining induced seismicity. Geophys Res Abstr 15, EGU2013-12871

Cupillard P, Stehly L, Romanowicz B (2011) The one-bit noise correlation: a theory based on the concepts of coherent and incoherent noise. Geophys J Int 184(2011):1397-1414. doi:10. 1111/j.1365-246X.2010.04923.x

De Natale G, Iannaccone Martini M, Zollo A (1987) Seismic sources and attenuation properties at the Campi Flegrei volcanic area. Pure Appl Geophys 125(6):883-917

Evans KF, Moriya H, Niitsuma H, Jones RH, Phillips WS, Genter A, Sausse J, Jung R, Baria R (2005) Microseismicity and permeability enhancement of hydrogeologic structures during massive fluid injections into granite at $3 \mathrm{~km}$ depth at the Soultz HDR site. Geophys J Int 160(1):388-412. doi:10.1111/j.1365-246X.2004.02474.X

Fitch TJ, McCowan DW, Shields MW (1980) Estimation of seismic moment tensor from teleseismic body wave data with application 
to intraplate and mantle earthquakes. J Geophys Res 85:3817-3828

Geller RJ, Mueller CS (1980) Four similar earthquakes in central California. Geophys Res Lett 7:821-824

Gibowicz SJ (2006) Seismic doublets and multiplets at Polish coal and copper mines. Acta Geophys 54(2):142-157. doi:10.2478/ s11600-006-0014-y

Gibowicz SJ (2009) Seismicity induced by mining: recent research. Adv Geophys 51:1-53

Gibowicz SJ, Kijko A (1994) An introduction to mining seismology. Academic Press, San Diego

Gibowicz SJ, Lasocki S (2001) Seismicity induced by mining: ten years later. Adv Geophys 44:39-181

Godano M, Bernard P, Dublanchet P (2015) Bayesian inversion of seismic spectral ratio for source scaling. Application to a persistent multiplet in the western Corinth rift. J Geophys Res 120(11):7683-7712. doi:10.1002/2015JB012217

Got JL, Frechet J, Klein FW (1994) Deep fault plane geometry inferred from multiplet relative relocation beneath the south flank of Kilauea. J Geophys Res 99:15375-15386

Gregersen S, Wiejacz P, Dębski W, Domanski B, Assinovskaya B, Guterch B, Mäntyniemi P, Nikulin VG, Pacesa A, Puura V, Aronov AG, Aronova TI, Grünthal G, Husebye ES, Sliaupa S (2007) The exceptional earthquakes in Kaliningrad District, Russia on September 21, 2004. Phys Earth Planet Inter 164(1-2):64-74. doi:10.1016/j.pepi.2007.06.005

Haskell NA (1953) The dispersion of surface waves in multilayered media. Bull Seismol Soc Am 43:17-34

Kagan YY, Jackson DD (1999) Worldwide doublets of large shallow earthquakes. Bull Seismol Soc Am 89:1147-1155

Kwiatek G, Ben-Zion Y (2013) Assessment of P and S wave energy radiated from very small shear-tensile seismic events in a deep South African mine. J Geophys Res 118:3630-3641. doi:10. 1002/jgrb.50274

Kwiatek G, Martinez-Garzon P, Bohnhoff M (2016) HybridMT: a $\mathrm{MATLAB} /$ shell environment package for seismic moment tensor inversion and refinement. Seismol Res Lett. doi:10.1785/ 0220150251

Lizurek G, Wiejacz P (2011) Moment tensor solution and physical parameters of selected recent seismic events at Rudna copper mine. In: Idziak AF, Dubiel R (eds) Geophysics in mining and environmental protection, Geoplanet: Earth and Planetary Sciences 2. Springer, Berlin

Madariaga R (1976) Dynamics of an expanding circular fault. Bull Seismol Soc Am 66:636-666

Niewiadomski J (1997) Spectral analysis and seismic source parameters. In: Mendecki AJ (ed) Seismic monitoring in mines. Chapman \& Hall, London, pp 144-158
Orlecka-Sikora B, Cesca S, Lasocki S, Lizurek G, Wiejacz P, Rudziński $Ł$ (2014) Seismogenesis of exceptional ground motion due to a sequence of mining induced tremors from LegnicaGłogów Copper District in Poland. Geophys J Int. doi:10.1093/ gji/ggu 109

Poupinet G, Ellsworth WL, Frechet J (1984) Monitoring velocity variations in the crust using earthquake doublets: an application to the Calaveras fault, California. J Geophys Res 89:5719-5731

Quintanar L, Rodríguez-González M, Campos-Enríquez O (2004) A shallow crustal earthquake doublet from the Trans-Mexican Volcanic Belt (Central Mexico). Bull Seismol Soc Am 94:845-855. doi:10.1785/0120030057

Rudziński Ł, Dębski W (2011) Extending the double-difference location technique to mining applications. Part I numerical study. Acta Geophys 59(4):785-814. doi:10.2478/511600-0110021-5

Rudziński $Ł$, Cesca S, Lizurek G (2016) Complex rupture process of the 19 March 2013, Rudna Mine (Poland) induced seismic event and collapse in the light of local and regional moment tensor inversion. Seismol Res Lett 87:274-284. doi:10.1785/ 0220150150

Schaff P, Waldhauser F (2005) Waveform cross-correlation-based differential travel-time measurements at the Northern California seismic network. Bull Seismol Soc Am 95(6):2446-2461. doi:10.1785/0120040221

Sen AT, Cesca S, Bischoff M, Meier T, Dahm T (2013) Automated full moment tensor inversion of coal mining-induced seismicity. Geophys J Int 195:1267-1281. doi:10.1093/gji/ggt300

Spottiswoode SM, Milev AM (1998) The use of waveform similarity to define planes of mining-induced seismic events. Tectonophysics 289:51-60

Waldhauser F, Ellsworth WL (2000) A double-difference earthquake location algorithm: method and application to the northern Hayward Fault, California. Bull Seismol Soc Am 90:1353-1363

Wehling-Benatelli S, Becker D, Bischoff M, Frederich W, Meier T (2013) Indication for different types of brittle failure due to active coal mining using waveform similarities of induced seismic events. Solid Earth Discuss 5:655-698. doi:10.5194/sed5-655-2013

Wessel P, Smith WHF (1998) New, improved version of the Generic Mapping Tools released. EOS Trans AGU 79:579

Wiejacz P (1992) Calculation of seismic moment tensor for mine tremors from the Legnica-Głogów Copper Basin. Acta Geophys Pol 40:103-122

Wyss M, Brune JN (1968) Seismic moment, stress and source dimensions for earthquakes in the California-Nevada region. J Geophys Res 73:4681-4694 